\title{
COVID-19 Vaccine Donations-Vaccine Empathy or Vaccine Diplomacy? A Narrative Literature Review
}

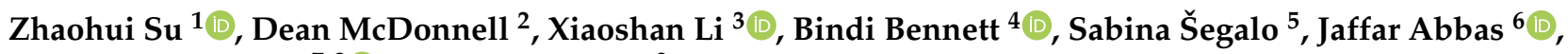 \\ Ali Cheshmehzangi ${ }^{7,8}\left(\mathbb{D}\right.$ and Yu-Tao Xiang ${ }^{9, *}$
}

1 Center on Smart and Connected Health Technologies, Mays Cancer Center, School of Nursing, UT Health San Antonio, San Antonio, TX 78229, USA; szh@utexas.edu

2 Department of Humanities, Institute of Technology, R93 V960 Carlow, Ireland; dean.mcdonnell@itcarlow.ie

3 Program of Public Relations and Advertising, Beijing Normal University-Hong Kong Baptist University United International College, Hong Kong 519087, China; xiaoshan.li@utexas.edu

4 University of the Sunshine Coast, Maroochydore, QLD 4558, Australia; bbennet1@usc.edu.au

5 Department of Microbiology, Faculty of Medicine, University of Sarajevo, 71000 Sarajevo, Bosnia and Herzegovina; sabina.segalo11@gmail.com

6 School of Media and Communication, Antai College of Economics and Management, Shanghai Jiao Tong University, Shanghai 200240, China; dr.abbas.jaffar@outlook.com

7 Department of Architecture and Built Environment, Faculty of Science and Engineering, University of Nottingham Ningbo China, Ningbo 315100, China; Ali.Cheshmehzangi@nottingham.edu.cn

8 Network for Education and Research on Peace and Sustainability (NERPS), Hiroshima University, Hiroshima 739-8527, Japan

9 Centre for Cognitive and Brain Sciences, Department of Public Health and Medicinal Administration, Faculty of Health Sciences, Institute of Translational Medicine, Institute of Advanced Studies in Humanities and Social Sciences, University of Macau, Macao 999078, China

Citation: Su, Z.; McDonnell, D.; Li, X.; Bennett, B.; Šegalo, S.; Abbas, J.; Cheshmehzangi, A.; Xiang, Y.-T. COVID-19 Vaccine DonationsVaccine Empathy or Vaccine Diplomacy? A Narrative Literature Review. Vaccines 2021, 9, 1024. https://doi.org/10.3390/ vaccines 9091024

Academic Editor: Barbara Rath

Received: 15 June 2021

Accepted: 4 August 2021

Published: 15 September 2021

Publisher's Note: MDPI stays neutral with regard to jurisdictional claims in published maps and institutional affiliations.

Abstract: Introduction: Vaccine inequality inflames the COVID-19 pandemic. Ensuring equitable immunization, vaccine empathy is needed to boost vaccine donations among capable countries. However, damaging narratives built around vaccine donations such as "vaccine diplomacy" could undermine nations' willingness to donate their vaccines, which, in turn, further exacerbate global vaccine inequality. However, while discussions on vaccine diplomacy are on the rise, there is limited research related to vaccine diplomacy, especially in terms of its characteristics and effects on vaccine distribution vis-à-vis vaccine empathy. Thus, to bridge the research gap, this study aims to examine the defining attributes of vaccine diplomacy and its potential effects on COVID-19 immunization, particularly in light of vaccine empathy. Methods: A narrative review was conducted to shed light on vaccine diplomacy's defining attributes and effects in the context of COVID-19 vaccine distribution and dissemination. Databases such as PubMed and Medline were utilized for literature search. Additionally, to ensure up-to-date insights are included in the review, validated reports and reverse tracing of eligible articles' reference lists in Google Scholar have also been conducted to locate relevant records. Results: Vaccine empathy is an individual or a nation's capability to sympathize with other individuals or nations' vaccine wants and needs, whereas vaccine diplomacy is a nation's vaccine efforts that aim to build mutually beneficial relationships with other nations ultimately. Our findings show that while both vaccine empathy and vaccine diplomacy have their strengths and weaknesses, they all have great potential to improve vaccine equality, particularly amid fast-developing and ever-evolving global health crises such as COVID-19. Furthermore, analyses show that, compared to vaccine empathy, vaccine diplomacy might be a more sustainable solution to improve vaccine donations mainly because of its deeper and stronger roots in multilateral collaboration and cooperation. Conclusion: Similar to penicillin, automated external defibrillators, or safety belts amid a roaring global health disaster, COVID-19 vaccines are, essentially, life-saving consumer health products that should be available to those who need them. Though man-made and complicated, vaccine inequality is nonetheless a solvable issue - gaps in vaccine distribution and dissemination can be effectively addressed by timely vaccine donations. Overall, our study underscores the instrumental and indispensable role of vaccine diplomacy in 
addressing the vaccine inequality issue amid the COVID-19 pandemic and its potentials for making even greater contributions in forging global solidarity amid international health emergencies. Future research could investigate approaches that could further inspire and improve vaccine donations among capable nations at a global scale to advance vaccine equity further.

Keywords: COVID-19; vaccination; inequality; vaccine diplomacy; vaccine empathy

\section{Introduction}

Vaccine distribution is often unequal [1]. The answer to who should have nonessentials, such as the best piano in the world, could be reasonably varied, ranging from the richest, the luckiest, or the most interested to the best pianist. The answer to who should have essentials such as the coronavirus disease 2019 (COVID-19) vaccines in the wake of a fast-deteriorating global pandemic, on the other hand, should be simple and straightforward; those who need COVID-19 vaccination the most. Similar to penicillin, automated external defibrillators, or safety belts, COVID-19 vaccines are, essentially, life-saving consumer health technologies [2] or products that should be available to those who need them in a timely fashion. This is particularly true in light of the ever-evolving COVID-19 mutations, such as the Delta variant [3], which are situations that further highlight why vaccinations remain the most straightforward path into a post-pandemic reality [4]. Then comes the rub: across the globe, especially in poorer countries [5], why is it that the world's most vulnerable communities to the pandemic - the old, the immunocompromised, and the frontline workers [6,7], are not given the vaccines they urgently needed to fend off COVID-19 infections and deaths?

\subsection{Vaccine Availability Equals to Vaccine Accessibility, Only for the Global North}

It is important to understand that global vaccine production has accelerated tremendously since it first became available-more than 12 billion vaccine doses will be produced in 2021 alone [1]. Yet ironically, or perhaps unsurprisingly, most of the available vaccines went to rich countries-as of 7 May 2021, high-income countries have grabbed approximately 5 billion COVID-19 vaccines, while on the other hand, low-income nations only managed to secure around 270 million doses [1]. Vaccine inequality has already been translated into health inequality; many thanks to a considerable surplus of COVID-19 vaccines, while North America has already vaccinated $30.57 \%$ of its population, followed by Europe (23.28\%) and South America (12.82\%), whereas continents, such as Asia and Africa, only have $4.48 \%$ and $1.01 \%$ of their populations vaccinated against the virus, respectively [7]. In other words, as rich countries such as the United States (U.S.) and Canada hoard doses up to five times their respective populations and counting [1], the Global South, countries ranging from India, Brazil, and Peru to Rwanda are still struggling and scrambling to secure vaccines to not only protect its most vulnerable from COVID-19 infections and deaths but also to prevent humanitarian crises from further deterioration [8]. Peru, for instance, although it has been shouldering a grim excess death rate (over-the-historicalaverage death toll) that is twice that of the U.S. [8], as of 7 May 2021, it only had 3.77\% of its population vaccinated compared to $44.69 \%$ COVID-19 vaccinations in the U.S. [7]. These sobering statistics indicate that, while vaccine inequality is on the rise, vaccine empathy is in short supply.

\subsection{The Humanitarian Imperative of Vaccine Empathy}

Though successful COVID-19 vaccination campaigns are contingent on many factors ranging from effective vaccine communication, vaccine efficacy, vaccine distribution, vaccine administration, to equitable vaccine accessibility [9-11], among all these factors, vaccine accessibility is perhaps the most important contributor upon which the rest of the components depend. For instance, debates about which vaccine is more efficacious or easier 
to transport are meaningless unless people have access to actual COVID-19 shots so that they can test their efficacy or transport them between places. Arguably, the most effective approach to bridging vaccine inequality, measured by the time needed for enabling those who want vaccines access to COVID-19 shots, is via vaccine sharing mechanisms, such as vaccines donated by the World Health Organization's (WHO) COVAX program [12]. Compared to other possible solutions to address the ever-widening vaccine inequality gap, ranging from waiving vaccine patents to building vaccine factories, vaccine donation is perhaps the most effective, efficient, and pressure-free alternative for vaccine have-nots to have access to COVID-19 vaccines in a timely fashion [13]. The time saved from pricing, payment, patent, manufacturing, delivery, administration, data procurement, along with the accompanying contractual negotiations, for instance, could translate into lives saved amid the continuing rampant pandemic; during the first week of May 2021, for instance, each hour, an average of 153 people died of COVID-19 in India alone [8].

It is important to note that, aiming to bridge vaccine inequality, countries across the world have been sharing their doses with those in need, especially nations equipped with vaccine development and production capabilities such as China, India, and Russia [14]. As of 5th May, outside of the COVAX vaccine distribution scheme, only five countries have made larger-than-100,000 donations to the vaccine have-nots: China (13.4 million), India (10.5 million), Turkey (190,000), Russia (158,000), and United Arab Emirates (UAE) $(120,000)$ [14]. Unfortunately, none of the top vaccine donor countries are rich western countries, including nations that have been hoarding COVID-19 vaccines from the getgo [1]. Naturally, particularly in light of distribution issues identified in the WHO's COVAX program (e.g., extremely slow roll-out) [15], a more hopeful alternative is for capable countries to show their vaccine empathy by sharing their vaccine surpluses with those in dire need. However, in light of the rampant vaccine nationalism sentiments [16] and the fact that COVID-19 herd immunity is difficult to achieve, particularly in light of vaccine hesitancy [10] and virulent mutations [17], it might become increasingly difficult for rich countries to share their "parked" COVID-19 doses [18].

The lack of vaccine donors might be further exacerbated by the toxic narratives that surround these vaccine donations, as countries that made the most COVID-19 donations are often referred to as "vaccine diplomats", undermining the humanitarian significance of sharing possibly the most precious and life-saving properties amid the pandemicCOVID-19 vaccines. In other words, rather than seeing vaccine donations as a display of vaccine empathy, by fixating on the possible reciprocal favors that vaccine donors may or may not receive in the future, many scholars frame these donations as purely a transaction in the scheme of vaccine diplomacy [19-22]. Yet interestingly, while discussions on vaccine diplomacy are on the rise, there is a shortage of insights on vaccine diplomacy and how it might similar to or differ from vaccine empathy. Thus, to bridge the research gap, this study aims to examine the characteristics and effects of vaccine diplomacy in the context of the pandemic, particularly in light of COVID-19 vaccine empathy.

\section{Methods}

A narrative literature review was conducted to identify the characteristics and effects of vaccine diplomacy in the context of COVID-19, vis-à-vis vaccine empathy amid the pandemic. The narrative review method was chosen because it is a powerful tool to help: (1) "identify what has been accomplished previously, allowing for consolidation, for building on previous work, for summation, for avoiding duplication and for identifying omissions or gaps" in a relatively nascent field that only limited research is expected to have conducted and published [23] and (2) build a conceptual understanding of the defining attributes of vaccine diplomacy based on the characteristics and effects identified [24]. We reviewed two representative databases, PubMed and Medline, for potentially eligible articles, using keywords that are focusing on two themes: vaccine diplomacy and the COVID-19 pandemic. The search terms used for PubMed and Medline could be found in Table 1 . In addition, ensuring that up-to-date insights are included in this review, validated 
reports and reverse tracing of eligible articles' reference lists in Google Scholar have also been conducted to locate additional relevant records.

Table 1. PubMed and Medline search strategy.

\begin{tabular}{|c|c|}
\hline Theme & Search String \\
\hline Vaccine Diplomacy & $\begin{array}{l}\text { diplomacy(MeSH) OR diplomacy(TIAB) OR “health diplomacy" (MeSH) OR “health diplomacy" (TIAB) } \\
\text { OR "medical diplomacy" (MeSH) OR "medical diplomacy"(TIAB) OR “vaccine diplomacy" (MeSH) OR } \\
\text { "vaccine diplomacy" (TIAB) OR “science diplomacy" (MeSH) OR “science diplomacy" (TIAB) }\end{array}$ \\
\hline COVID-19 & $\begin{array}{c}\text { ((coronavirus OR “corona virus" OR coronavirinae OR coronaviridae OR betacoronavirus OR covid19 } \\
\text { OR “covid 19" OR nCoV OR “CoV 2" OR CoV2 OR sarscov2 OR 2019nCoV OR "novel CoV” AND } \\
\text { ("severe acute respiratory" OR pneumonia) AND (outbreak)) OR “Coronavirus"(Mesh) OR } \\
\text { "Coronavirus Infections"(Mesh) OR “COVID-19" (Supplementary Concept) OR “severe acute respiratory } \\
\text { syndrome coronavirus 2" (Supplementary Concept) OR “Betacoronavirus"(Mesh)) }\end{array}$ \\
\hline
\end{tabular}

\section{Inclusion and Exclusion Criteria}

The full list of the inclusion criteria we adopted to screen articles could be found in Table 2. Overall, we excluded records if they are: (1) not written in English, (2) not focusing on vaccine-related diplomacy, (3) not centering on the COVID-19 vaccine, and (4) not providing detailed information on the attributes or effects of vaccine diplomacy in the context of COVID-19.

Table 2. Study inclusion criteria.

\begin{tabular}{cc}
\hline Data Type & Inclusion Criteria \\
\hline Language & English \\
$\begin{array}{c}\text { Study context } \\
\text { Vaccine type }\end{array}$ & $\begin{array}{c}\text { Vaccine diplomacy in the wake of COVID-19 } \\
\text { COVID-19 vaccines }\end{array}$ \\
Study design & $\begin{array}{c}\text { Provides detailed information on the attributes and effects of vaccine diplomacy } \\
\text { in the context of COVID-19 }\end{array}$ \\
\hline
\end{tabular}

\section{Results}

The database search was conducted on 10 May 2021. Only articles published between January 2020 to May 2021 were considered. After removing duplicates and screening the remaining records against the inclusion and exclusion criteria, 12 articles were selected for the final review and analysis. Key characteristics of these articles can be found in Table 3. In the following section, we will elaborate on study findings as well as their implications for future vaccine practices amid COVID-19 and beyond.

Table 3. Key articles included in the analysis.

\begin{tabular}{|c|c|c|c|c|c|}
\hline Author & Year & Country* & Title & Policy Focus & Vaccine Diplomacy Position \\
\hline AlKhaldi et al. [25] & 2021 & Canada & $\begin{array}{c}\text { Rethinking and } \\
\text { strengthening the Global } \\
\text { Health Diplomacy through } \\
\text { triangulated nexus between } \\
\text { policy makers, scientists, } \\
\text { and the community in light } \\
\text { of the COVID-19 } \\
\text { global crisis }\end{array}$ & Global & For \\
\hline Bollyky et al. [26] & 2021 & U.S. & $\begin{array}{l}\text { A year out: Addressing } \\
\text { international impacts of the } \\
\text { COVID-19 pandemic }\end{array}$ & U.S. & For \\
\hline Chattu et al. [27] & 2021 & Canada & $\begin{array}{l}\text { Global health diplomacy at } \\
\text { the intersection of trade and } \\
\text { health in the COVID-19 era }\end{array}$ & Global & For \\
\hline
\end{tabular}


Table 3. Cont.

\begin{tabular}{|c|c|c|c|c|c|}
\hline Author & Year & Country* & Title & Policy Focus & Vaccine Diplomacy Position \\
\hline Guidry et al. [18] & 2021 & U.S. & $\begin{array}{l}\text { U.S. public support for } \\
\text { COVID-19 vaccine donation } \\
\text { to low- and middle-income } \\
\text { countries during the } \\
\text { COVID-19 pandemic }\end{array}$ & U.S. & For \\
\hline Javed et al. [28] & 2020 & China & $\begin{array}{l}\text { Strengthening the } \\
\text { COVID-19 pandemic } \\
\text { response, global leadership, } \\
\text { and international } \\
\text { cooperation through global } \\
\text { health diplomacy }\end{array}$ & Global & For \\
\hline Kobierecka et al. [19] & 2021 & Poland & $\begin{array}{l}\text { Coronavirus diplomacy: } \\
\text { Chinese medical assistance } \\
\text { and its } \\
\text { diplomatic implications }\end{array}$ & China & For \\
\hline $\begin{array}{l}\text { Lancet Commission on } \\
\text { COVID-19 Vaccines } \\
\text { and Therapeutics Task } \\
\text { Force Members [29] }\end{array}$ & 2021 & U.K. & $\begin{array}{l}\text { Operation Warp Speed: } \\
\text { Implications for global } \\
\text { vaccine security }\end{array}$ & Global & For \\
\hline Pannu et al. [30] & 2021 & U.S. & $\begin{array}{l}\text { The state inoculates: } \\
\text { Vaccines as soft power }\end{array}$ & Global & Against \\
\hline Sharun et al. [31] & 2021 & India & $\begin{array}{l}\text { COVID-19 vaccine } \\
\text { diplomacy and equitable } \\
\text { access to vaccines amid } \\
\text { ongoing pandemic }\end{array}$ & India & For \\
\hline Sharun et al. [32] & 2021 & India & $\begin{array}{l}\text { India's role in COVID-19 } \\
\text { vaccine diplomacy }\end{array}$ & India & For \\
\hline Usher et al. [22] & 2021 & U.K. & $\begin{array}{l}\text { Uncertainties over EU } \\
\text { COVID-19 vaccine } \\
\text { sharing scheme }\end{array}$ & EU & Against \\
\hline Vanderslott et al. [33] & 2020 & U.K. & $\begin{array}{l}\text { Health diplomacy across } \\
\text { borders: The case of yellow } \\
\text { fever and COVID-19 }\end{array}$ & Global & For \\
\hline
\end{tabular}

Note. * Country refers to the first author's affiliation location. EU: European Union; U.K.: the United Kingdom; U.S.: the United States.

\section{Discussion}

Vaccine inequality undermines the speed, solidarity, and significance of society's collective fight against the COVID-19 pandemic [34]. Though vaccine donations have the potential to bridge vaccine inequality across the globe effectively and efficiently, these timely rescues are often negatively referred to as and narrowly summed into "vaccine diplomacy", often without offering a definition of the term [35-37]. However, particularly in light of vaccine nationalism [38], while the use and abuse of the term vaccine diplomacy could harm global vaccine collaborations (e.g., vaccine donations and vaccine loans [39]), there is a dearth of research in the literature. Thus, to address the research gap, this study sets out to investigate the characteristics and effects of vaccine diplomacy in the context of COVID-19 vaccine distribution. Specifically, we aim to find out the defining attributes of vaccine diplomacy vis-à-vis those of vaccine empathy and both practices' potential effects on addressing vaccine inequality.

Overall, our results suggest that while vaccine diplomacy and vaccine empathy have their strengths and weaknesses, they both have substantial potential to improve vaccine equity. Diplomacy is "the art of conducting relationships for gain without conflict [40]". Vaccine diplomacy, in the context of this study, could be understood as a nation's vaccine 
efforts that aim to build mutually beneficial relationships with other nations. Empathy, on the other hand, is "noticing another person's feelings, making an inference of the mental state of another, and responding appropriately to that person's state of mind [41]". Vaccine empathy, in turn, could be understood as an individual or a nation's capability to sympathize with other individuals or nations' vaccine wants and needs. It is important to note that while the relationship between vaccine empathy and vaccine diplomacy could be mutually exclusive, it is also possible that vaccine diplomacy is a subset of vaccine empathy. An illustration of the possible relationships between these two concepts could be found in Figure 1.

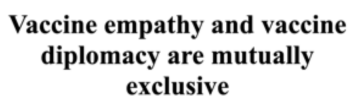

\section{Vaccine empathy overlaps vaccine diplomacy}

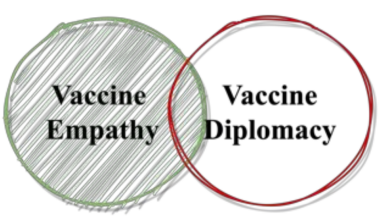

\section{Vaccine diplomacy is a subset} of vaccine empathy

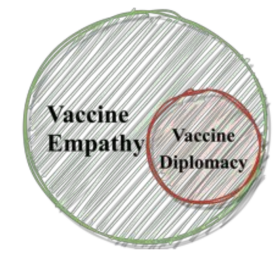

Figure 1. Paradigms for relationships between vaccine empathy and vaccine diplomacy.

However, vaccine donations, regardless of whether they are a result of vaccine empathy or vaccine diplomacy, could have a positive impact on the ever-increasingly widening vaccine inequality. Interestingly, the results of our narrative review suggest that, different from the makeup of news reports or other insights in mass media [35-37], the majority of scholarly articles on vaccine diplomacy published amid the pandemic supported the practice $[18,19,25-29,31-33]$ with only two $[22,30]$ of the twelve records expressing concerns about potential domestic backlash for donating vaccines. Our findings suggest that what WHO officials indicated on 11 May 2021, when they state that "vaccine diplomacy is not cooperation" and only "clear and clean cooperation" could yield benefits to pandemic prevention and control [42], might be in direct contrast to most academics' positions on vaccine diplomacy $[18,19,25-29,31-33]$. While some criticisms towards vaccine diplomacy seem to be not completely unfounded, as the scale and severity of COVID-19 might make any potential future expected gains associated with these donations seem uncaring, possibly bordering on unsympathetic [19], the significance of the potential sustainability of vaccine diplomacy, which has deeper and stronger roots in multilateral cooperation and collaboration compared with vaccine empathy, along with how this sustainability might impact COVID-19 vaccine donations in the long run, should not be overlooked.

Arguably, though COVAX was spearheaded by the WHO, it is difficult to not consider countries that donated to the program as not practicing vaccine diplomacy, particularly in light of the presence of rotating media reports. It is also important to factor in the fact that vaccine donations can hardly be carried out by individuals, as opposed to nationspartially due to COVID-19 vaccines' limited availability, high maintenance (e.g., reliance on sophisticated freezers), and unwavering demand [20,21]. These doses can hardly be donated anonymously or not in the form of "vaccine diplomacy". These insights combined suggest that COVID-19 vaccine donations might almost always be associated with a nation donor, even under WHO's COVAX program and in light of vaccine diplomacy. Detailed information on the defining attributes of vaccine empathy and vaccine diplomacy can be found in Table 4. 
Table 4. Definitions and defining characteristics of vaccine empathy and vaccine diplomacy.

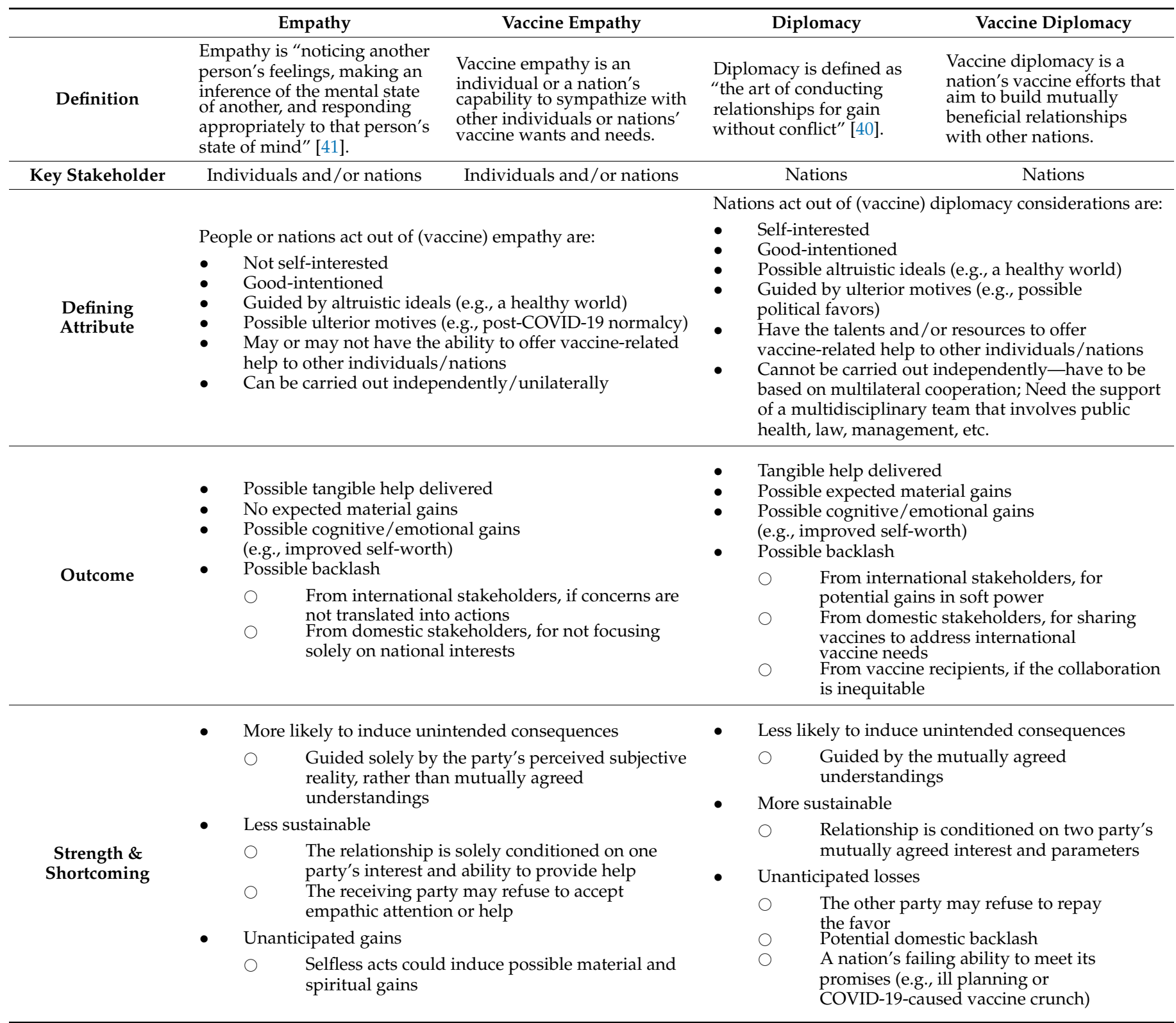

Our analyses indicate that, in contrast to vaccine diplomacy, vaccine empathy can exist independently of international collaborations and may not necessarily lead to actions or practices that improve vaccine equality. For instance, while many countries, including vaccine hoarders, such as the U.S. and Canada, might hold considerable vaccine empathy towards vaccine have-nots, due to factors such as lack of vaccine resources or domestic political pressure [18], they may not have the ability to act on their empathic emotions or thoughts. Findings further show that vaccine diplomacy could be a more effective and sustainable solution to address the issue of vaccine inequality, many thanks to its deeper roots in international collaboration and cooperation compared to vaccine empathy [43-45]. Furthermore, our results suggest that vaccine diplomacy's sustainability could often translate into a continued commitment to vaccine donations, reciprocal relationships between the donor and recipient countries of the vaccines, and limited unintended consequences imposed on the recipient countries due to potential agreements, if not binding contracts, associated with the donations. In essence, ranging from short-term vaccine donations to long-term international collaborations, vaccine diplomacy reinforces positive actions 
that improve vaccine equality and reinforce global solidarity, which, in turn, provides much-needed help and humanity in a pandemic-beaten society.

It is important to note that although COVID-19 vaccine donor nations may expect future favors returned with their donations, these favors may or may not become realized in the future. In particular, due to lack of precedence, it is possible that what happens amid the once-in-a-century COVID-19 pandemic stays in the pandemic. Not to mention that countries that donate their vaccines, as we have seen from India's example [46], are taking substantially greater risks compared to hoarder nations, such as becoming more vulnerable to potential future COVID-19 outbreaks and more prone to facing domestic backlash. In other words, considering the concrete vaccines donated, tangible inequality gaps bridged, and the positive sentiments associated with vaccine empathy displayed and delivered via doses shared, along with the possibility of no reciprocal favors returned post-pandemic and the considerable domestic pressures donor nations shoulder, greater acknowledgment, if not more encouragement, should be given to countries that endorse vaccine diplomacy. These insights combined suggest that, rather than pouring negative narratives to dampen the significance of bridging vaccine inequality via vaccine donations, it is perhaps more meaningful to appreciate and applaud both vaccine empathy and vaccine diplomacy in light of their results; improved COVID-19 vaccine equality, lives and livelihoods saved, as well as common humanity and global solidarity forged and reinforced.

\section{Limitations}

While this study fills important research gaps, it is not without limitations. First of all, our review is limited in scale and scope, which means that the insights provided in the analysis could be limited. Furthermore, the methodology we adopted is a narrative review approach, which, compared to methods such as systematic reviews, is limited in reproducibility and replicability [23].

\section{Conclusions}

Vaccine inequality, though man-made and complicated, is nonetheless a solvable issue-gaps in vaccine distribution and dissemination can be effectively addressed by timely vaccine donations that are enabled by vaccine diplomacy if not necessarily vaccine empathy. In this study, we examined the defining attributes of vaccine diplomacy and its potential effects on COVID-19 immunization in light of vaccine empathy. Albeit its shortcomings, the results underscore the instrumental and indispensable role of vaccine diplomacy in bridging the vaccine inequality issue amid the pandemic. Future research could investigate ways that could inspire and improve vaccine donations among vaccinerich nations, especially countries that tend to hoard their vaccine surpluses, at a global scale to advance vaccine equity further so that society at large can start to build better together.

Author Contributions: Z.S. conceived the work, reviewed the literature, drafted, and edited the manuscript. X.L., B.B., D.M., Š.S., J.A., A.C. and Y.-T.X. reviewed the literature and edited the manuscript. All authors have read and agreed to the published version of the manuscript.

Funding: This research received no external funding.

Institutional Review Board Statement: Not applicable.

Informed Consent Statement: Not applicable.

Data Availability Statement: While this paper does not report raw data, all information highlighted can be sourced in the original papers published using the references below.

Acknowledgments: The authors wish to express their gratitude to the editor and reviewers for their constructive insights and kind feedback.

Conflicts of Interest: The authors declare no conflict of interest. 


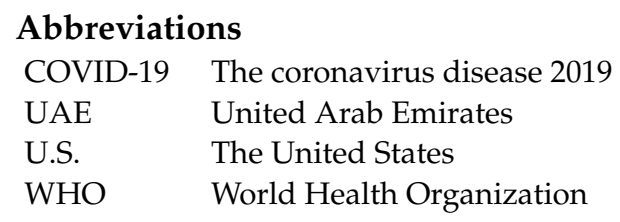

\section{References}

1. Duke Global Health Innovation Center. Interactive COVAX Map. Available online: https://launchandscalefaster.org/COVID-19 (accessed on 28 June 2021).

2. Su, Z.; Chengbo, Z.; Mackert, M. Understanding the influenza vaccine as a consumer health technology: A structural equation model of motivation, behavioral expectation, and vaccine adoption. J. Commun. Healthc. 2019, 12, 170-179. [CrossRef]

3. Lopez Bernal, J.; Andrews, N.; Gower, C.; Gallagher, E.; Simmons, R.; Thelwall, S.; Stowe, J.; Tessier, E.; Groves, N.; Dabrera, G.; et al. Effectiveness of Covid-19 Vaccines against the B.1.617.2 (Delta) Variant. N. Engl. J. Med. 2021, 385, 585-594. [CrossRef]

4. Polack, F.P.; Thomas, S.J.; Kitchin, N.; Absalon, J.; Gurtman, A.; Lockhart, S.; Perez, J.L.; Pérez Marc, G.; Moreira, E.D.; Zerbini, C.; et al. Safety and efficacy of the BNT162b2 mRNA Covid-19 vaccine. N. Engl. J. Med. 2020, 383, 2603-2615. [CrossRef]

5. Oli, S.; Nepal Is Being Overwhelmed by Covid. We Need Help. Available online: https:/ /www.theguardian.com/commentisfree/ 2021/may/10/nepal-covid-uk-g7 (accessed on 12 May 2021).

6. The Lancet. COVID-19 in India: The dangers of false optimism. Lancet 2020, 396, 867. [CrossRef]

7. Our World in Data. Coronavirus (COVID-19) Vaccinations. Available online: https://ourworldindata.org/covid-vaccinations (accessed on 28 June 2021).

8. Johns Hopkins University. The COVID-19 Global Map. Available online: https://coronavirus.jhu.edu/map.html (accessed on 2 August 2021).

9. $\mathrm{Su}, \mathrm{Z} . ;$ McDonnell, D.; Cheshmehzangi, A.; Li, X.; Maestro, D.; Šegalo, S.; Ahmad, J. With great hopes come great expectations: Access and adoption issues associated with COVID-19 vaccines. JMIR Public Health Surveill 2021, 10, 26111. [CrossRef] [PubMed]

10. Su, Z.; Wen, J.; Abbas, J.; McDonnell, D.; Cheshmehzangi, A.; Li, X.; Ahmad, J.; Šegalo, S.; Maestro, D.; Cai, Y. A race for a better understanding of COVID-19 vaccine non-adopters. Brain Behav. Immun. Health 2020, 9, 100159. [CrossRef]

11. Su, Z.; Wen, J.; McDonnell, D.; Goh, E.; Li, X.; Šegalo, S.; Ahmad, J.; Cheshmehzangi, A.; Xiang, Y.-T. Vaccines are not yet a silver bullet: The imperative of continued communication about the importance of COVID-19 safety measures. Brain Behav. Immun. Health 2021, 12, 100204. [CrossRef] [PubMed]

12. World Health Organization. COVAX: Working for Global Equitable Access to COVID-19 Vaccines. Available online: https: / / www.who.int/initiatives/act-accelerator/covax (accessed on 9 May 2021).

13. Nhamo, G.; Chikodzi, D.; Kunene, H.P.; Mashula, N. COVID-19 vaccines and treatments nationalism: Challenges for low-income countries and the attainment of the SDGs. Glob. Public Health 2021, 16, 319-339. [CrossRef] [PubMed]

14. The Economist. Covid-19 Vaccine Donations Have Yet to Take Off. Available online: https://www.economist.com/graphicdetail/2021/05/05/covid-19-vaccine-donations-have-yet-to-take-off (accessed on 8 May 2021).

15. Mueller, B.; Robbins, R. Where a Vast Global Vaccination Program Went Wrong. Available online: https://www.nytimes.com/20 21/08/02/world/europe/covax-covid-vaccine-problems-africa.html (accessed on 3 August 2021).

16. Eaton, L. Covid-19: WHO warns against “vaccine nationalism" or face further virus mutations. BMJ 2021, 372, n292. [CrossRef] [PubMed]

17. Corum, J.; Zimmer, C. Coronavirus Variants and Mutations. Available online: https://nyti.ms/3jue0k1 (accessed on 2 July 2021).

18. Guidry, J.P.D.; Perrin, P.B.; Laestadius, L.I.; Vraga, E.K.; Miller, C.A.; Fuemmeler, B.F.; Burton, C.W.; Ryan, M.; Carlyle, K.E. U.S public support for COVID-19 vaccine donation to low- and middle-income countries during the COVID-19 pandemic. Vaccine 2021, 39, 2452-2457. [CrossRef] [PubMed]

19. Kobierecka, A.; Kobierecki, M.M. Coronavirus diplomacy: Chinese medical assistance and its diplomatic implications. Int. Politics 2021, 1-18. [CrossRef]

20. Baraniuk, C. Covid-19: What do we know about Sputnik V and other Russian vaccines? BMJ 2021, 372, n743. [CrossRef] [PubMed]

21. Aisha Ibrahim Mohammed, D.S.C.C. The global vaccine competitions: An overview of COVID-19. Eur. J. Mol. Clin. Med. 2021, 7 , 3882-3898.

22. Usher, A.D. Uncertainties over EU COVID-19 vaccine sharing scheme. Lancet 2021, 397, 1171. [CrossRef]

23. Grant, M.J.; Booth, A. A typology of reviews: An analysis of 14 review types and associated methodologies. Health Inf. Libr. J. 2009, 26, 91-108. [CrossRef]

24. Ramírez, J.; Valdivia, L.; Rivera, E.; da Silva Santos, M.; Sepúlveda, D.; Labonté, R.; Ruckert, A. Chile's role in global health diplomacy: A narrative literature review. Glob. Health 2018, 14, 108. [CrossRef] [PubMed]

25. AlKhaldi, M.; James, N.; Chattu, V.K.; Ahmed, S.; Meghari, H.; Kaiser, K.; Ijsselmuiden, C.; Tanner, M. Rethinking and strengthening the global health diplomacy through triangulated nexus between policy makers, scientists and the community in light of COVID-19 global crisis. Glob. Health Res. Policy 2021, 6, 12. [CrossRef] [PubMed]

26. Bollyky, T.J. A Year Out: Addressing International Impacts of the COVID-19 Pandemic; Council on Foreign Relations: New York, NY, USA, 2021 
27. Chattu, V.K.; Pooransingh, S.; Allahverdipour, H. Global health diplomacy at the intersection of trade and health in the COVID-19 era. Health Promot. Perspect. 2021, 11, 1-4. [CrossRef]

28. Javed, S.; Chattu, V.K. Strengthening the COVID-19 pandemic response, global leadership, and international cooperation through global health diplomacy. Health Promot. Perspect. 2020, 10, 300-305. [CrossRef]

29. Lancet Commission on Covid-Vaccines Therapeutics Task Force Members. Operation Warp Speed: Implications for global vaccine security. Lancet Glob Health 2021, 9, e1017-e1021. [CrossRef]

30. Pannu, J.; Barry, M. The state inoculates: Vaccines as soft power. Lancet Glob. Health 2021, 9, e744-e745. [CrossRef]

31. Sharun, K.; Dhama, K. COVID-19 vaccine diplomacy and equitable access to vaccines amid ongoing pandemic. Arch. Med. Res. 2021. [CrossRef] [PubMed]

32. Sharun, K.; Dhama, K. India's role in COVID-19 vaccine diplomacy. J. Travel Med. 2021. [CrossRef]

33. Vanderslott, S.; Marks, T. Health diplomacy across borders: The case of yellow fever and COVID-19. J. Travel Med. 2020, 27, taaa112. [CrossRef] [PubMed]

34. Mehrotra, N.; Saaliq, S. Vaccine Inequality in India Sends Many Falling through Gaps. Available online: https://apnews.com/ article/india-technology-coronavirus-pandemic-business-health-9fc262598b4a6e1fc5ff223fdd748cea (accessed on 29 May 2021).

35. Palmer, J. China's Vaccine Diplomacy Has Mixed Results. Available online: https://foreignpolicy.com/2021/04/07/chinacoronavirus-vaccine-diplomacy-sinovac-sinopharm-mixed-results / (accessed on 12 May 2021).

36. Jennings, M. Vaccine Diplomacy: How Some Countries Are Using COVID to Enhance Their Soft Power. Available online: https: / / theconversation.com/vaccine-diplomacy-how-some-countries-are-using-covid-to-enhance-their-soft-power-155697 (accessed on 12 May 2021).

37. Hui, M. China's Vaccine Diplomacy Has an Aggressive Anti-Vax Element. Available online: https:/ / qz.com/1959855/chinascoronavirus-vaccine-diplomacy-is-anti-vax/ (accessed on 12 May 2021).

38. Lagman, J.D.N. Vaccine nationalism: A predicament in ending the COVID-19 pandemic. J. Public Health 2021, 43, e375-e376. [CrossRef] [PubMed]

39. Agren, D.; Cecco, L. US to Send 4m AstraZeneca Vaccine Doses to Mexico and Canada. Available online: https://www. theguardian.com/world/2021/mar/18/us-astrazeneca-vaccine-doses-mexico-canada (accessed on 12 May 2021).

40. Muthanna, K.A. Military diplomacy. J. Def. Stud. 2011, 5, 1-15.

41. Amiruddin, A.; Fueggle, S.N.; Nguyen, A.T.; Gignac, G.E.; Clunies-Ross, K.L.; Fox, A.M. Error monitoring and empathy: Explorations within a neurophysiological context. Psychophysiology 2017, 54, 864-873. [CrossRef] [PubMed]

42. The Times of India. WHO Chief Slams 'Vaccine Diplomacy' in Covid Fight. Available online: https:/ / timesofindia.indiatimes. com/world/europe/who-chief-slams-vaccine-diplomacy-in-covid-fight/articleshow/82542370.cms (accessed on 12 May 2021).

43. Hotez, P.J. Peace through vaccine diplomacy. Science 2010, 327, 1301. [CrossRef] [PubMed]

44. Hotez, P.J. "Vaccine diplomacy": Historical perspectives and future directions. PLoS Negl. Trop. Dis. 2014, 8, e2808. [CrossRef]

45. Hotez, P.J. Russian-United States vaccine science diplomacy: Preserving the legacy. PLoS Negl. Trop. Dis. 2017, 11, e0005320. [CrossRef] [PubMed]

46. Bhuyan, A. Experts criticise India's complacency over COVID-19. Lancet 2021, 397, 1611-1612. [CrossRef] 